May 2013

\title{
The Singer and the Violinist: When Pro-Abortion Ethicists Are Out of Tune
}

Tyler M.John

Cedarville University, tmjohn@cedarville.edu

DigitalCommons@Cedarville provides a publication platform for fully open access journals, which means that all articles are available on the Internet to all users immediately upon publication. However, the opinions and sentiments expressed by the authors of articles published in our journals do not necessarily indicate the endorsement or reflect the views of DigitalCommons@Cedarville, the Centennial Library, or Cedarville University and its employees. The authors are solely responsible for the content of their work. Please address questions to dc@cedarville.edu.

\section{Recommended Citation}

John, Tyler M. (2013) "The Singer and the Violinist: When Pro-Abortion Ethicists Are Out of Tune," CedarEthics: A Journal of Critical Thinking in Bioethics: Vol. 12 : No. 2 , Article 3.

DOI: $10.15385 /$ jce.2013.12.2.3

Available at: http://digitalcommons.cedarville.edu/cedarethics/vol12/iss2/3 


\title{
The Singer and the Violinist: When Pro-Abortion Ethicists Are Out of Tune
}

Browse the contents of this issue of CedarEthics: A Journal of Critical Thinking in Bioethics.

\begin{abstract}
In the fall of 1971, Philosophy \& Public Affairs published an essay by feminist moral philosopher Judith Jarvis Thomson that would have the entire nation talking. Her piece soon became one of the most widely cited and reprinted essays in the Western world, and one of the most influential essays on the issue of abortion. In her essay, "A Defense of Abortion," Thomson undertook the seemingly impossible task of explaining why, in her view, it is morally permissible to abort a human fetus even if the fetus is granted the status of personhood. The essay has received both support and recognition from many pro-choice ethicists, clearly seen just by virtue of the article's overwhelming popularity. Yet prominent Australian-American ethicist and moral philosopher Peter Singer finds the argument to be deeply and irredeemably flawed. Some may be puzzled to know that the same scholar that believes that both infanticide and euthanasia are obvious necessities also believes that the most prominent abortion argument in history is an extremely weak one.
\end{abstract}

\section{Keywords}

Abortion, ethics

\section{Creative Commons License}

\section{(c) $(1) \Theta(\Theta$}

This work is licensed under a Creative Commons Attribution-Noncommercial-No Derivative Works 3.0 License.

Follow this and additional works at: http:// digitalcommons.cedarville.edu/cedarethics

Part of the Bioethics and Medical Ethics Commons 


\title{
The Singer and the Violinist: When Pro-Abortion Ethicists are out of Tune
}

\author{
Tyler John \\ Cedarville University
}

$\mathrm{I}$ n the fall of 1971, Philosophy \& Public Affairs published an essay by feminist moral philosopher Judith Jarvis Thomson that would have the entire nation talking. Her piece soon became one of the most widely cited and reprinted essays in the Western world, and one of the most influential essays on the issue of abortion. In her essay, "A Defense of Abortion," Thomson undertook the seemingly impossible task of explaining why, in her view, it is morally permissible to abort a human fetus even if the fetus is granted the status of personhood. The essay has received both support and recognition from many pro-choice ethicists, clearly seen just by virtue of the article's overwhelming popularity. Yet prominent Australian-American ethicist and moral philosopher Peter Singer finds the argument to be deeply and irredeemably flawed. Some may be puzzled to know that the same scholar that believes that both infanticide and euthanasia are obvious necessities also believes that the most prominent abortion argument in history is an extremely weak one.

Michael Specter calls Singer "the most controversial philosopher alive", and wonders if Singer believes that people should be treated like animals (1999). The outcry against the hiring of Singer at Princeton University by multiple groups of diverse interests, ranging from Princeton alumni (Ruderman, 2000) to disability rights groups (MacFarquhar, 1999), was enormous. This all resulted in a number of arrests at demonstrations against Singer, and many pledges to divert donations away from Princeton's endowment. The protests were based on an opposition to Singer's seeming disregard for human life, especially the life of the unborn and the handicapped.

Therefore it may surprise many conservatives to find that Singer's preference utilitarianism could actually serve as a powerful ally against some of arguments for abortion, including Thomson's. In this essay, I will show that Thomson's argument for abortion fails on consequentialist grounds. I will further demonstrate that consequentialism, despite its negative public reputation, is a particularly powerful tool for getting at the truth of moral matters, even for the most conscientious defenders of human life at every stage of development.

In "A Defense of Abortion," Thomson grants the conservative defenders of the "sanctity of life" the premise that humans are persons from the moment of conception. From there, she presents us with a thought experiment: you wake up one morning to find that you are lying back to back with an unconscious man. You are told that he is a famous violinist, gravely ill with a fatal kidney ailment, and that you alone have the necessary blood type to save him from an otherwise certain death. Your kidnappers, the Society of Music Lovers, have connected his circulatory system to your kidneys so that they can filter poisons from the musician's blood. To unplug the violinist would be to kill him, but if you remain attached to the violinist for a "mere" nine months he will recover and can go about his life.

CedarEthics, vol. 12, no. 2, pp. 13-19. ISSN 2333-9713

(C) 2013, Tyler John, licensed under CC BY-NC-ND

(http://creativecommons.org/licenses/by-nc-nd/3.0/) 
Thomson thinks that it would be awfully nice of you to remain attached to the violinist and save his life, but that you are by not obligated to keep the him alive. In other words, you have a right to unplug the violinist and regain your autonomy at a moment of your choosing, and this would not be blameworthy (Thomson, 1971).

Thomson's thought experiment is intended to be analogous with an unwanted pregnancy. Even if the aborted fetus is a human person worthy of the same rights as any other person, the mother has no necessary obligation to the child, and is permitted to disconnect herself from the child, ending its life, if she so desires. It would be awfully nice of her to sacrifice her autonomy and spare the child, but she is by no means morally obligated to do so.

Many ethicists have opposed Thomson's argument on the basis of disanalogy, arguing that, though the thought experiment is compelling, it is in no way similar to the average pregnancy (Koukl, 2003). However, Singer finds the analogy ingenious, but believes that the woman who finds herself in this situation ought to remain attached to the violinist. Thus, even if the reader's relationship with the violinist is considered perfectly analogous to a mother's relationship with her child, there is no strong argument for abortion to be found within Thomson's essay.

In fact, if one assumes that all human fetuses are human persons and that the unconscious violinist thought experiment is relevantly analogous to a normal pregnancy, one might find it a compelling moral argument against abortion on the basis of preference utilitarianism or another form of consequentialism. In Practical Ethics, Singer explains that Thomson's argument "is sound if the particular theory of rights that lies behind it is sound; and it is unsound if that theory of rights is unsound" (Singer, 2011, p. 148). So, if Thomson is correct in believing that persons have a right to maintain full control over themselves, and cannot be morally required to give up their autonomy for the sake of another, then Thomson is also correct that a mother's abortion of the life of her child, a human person, is morally permissible. If this belief is false, then her argument is unsound, and such an action is impermissible. Although it may not be immediately clear to some that Thomson's theory of rights is false, Singer clearly thinks that it is.

To see why such a particular theory of rights undergirds Thomson's moral philosophy, we can look to another of her thought experiments. Thomson poses an example wherein "[I am] desperately ill, and the only thing that can save my life is the touch of my favorite film star's cool hand on my fevered brow" (Singer, 2000, p. 154). According to Thomson, even though I have a right to life, I do not have a right to force the film star to come to me and touch my forehead. Furthermore, the movie star is under no moral obligation to do so even if it costs him very little. This case is very similar to the violinist thought experiment. According to Thomson, it would be awfully nice of the film star to save my life, but it is morally permissible for him to refuse to do so.

Peter Singer, a consequentialist, rejects this theory of rights and believes that it is morally permissible (and, in fact, obligatory) to unplug the violinist only if, on balance, the consequences of doing so are better than the consequences of remaining attached to the violinist. Similarly, according to consequentialists, if the consequences of your favorite film star's touching your brow and healing you from your horrible and terminal illness are greater than the consequences 
of his not doing so, then it is morally obligatory for the film star to travel to you and heal you of your illness. This seems to be an intuitive result - of course the movie star ought to do so. To fail to do so would involve complicity in your death, an act on par with some cases of murder.

Now even a rejection of Thomson's theory of rights does not provide us with a summary moral judgment as to whether it would actually be morally impermissible to remove yourself from the violinist if you were in the situation described by Thomson. It seems clear that undermining Thomson's moral framework does not utterly defeat her argument for abortion. After all, many find the argument both intuitive and plausible, at least on a first reading. Can Thomson's argument stand up under a consequentialist's scrutiny?

Peter Singer is a consequentialist, and teaches that a morally right act is that which produces the best consequences. A morally impermissible act is, then, any act that fails to produce the best consequences. There are many different varieties of consequentialism, each with varying axiologies that tell us what sorts of goods exist. Different forms of consequentialism try to uncover what consequences are important, in order to help us determine what the best consequences are. Singer adheres to a form of consequentialism known as "preference utilitarianism," where the best consequences are those that "satisfy the most preferences, weighed in accordance with the strength of the preferences" (Singer, 1997). This is in contradistinction to classical utilitarianism, an older form of consequentialism that defines the best consequences as those that maximize pleasure and minimize pain.

On the view of classical utilitarianism, only consciously-recognized pleasures and pains have moral recognition. This leads to several unfortunate results, including that death may not be bad for the person who dies (since there is nothing painful about death in itself). Likewise, there may be nothing wrong with doing seemingly obscene and violent things to an unconscious person (at least, perhaps, until he wakes up), or that engaging in "peeping Tom" activities is morally obligatory, as it is surely pleasurable for the one "peeping" and clearly not recognizably displeasurable for the one being watched.

For the preference utilitarian, on the other hand, showing the immorality of these actions is simple. Each of these actions violates the preferences of an individual. For most people, death is not preferential to life. Even an unconscious person has preferences, despite his inability to recognize them while he remains unconscious. A woman being watched through her window has the preference to not be watched, even if she does not know that she is being watched. We also take some preferences, like the preference to remain alive, to be particularly strong (whether the one who holds the preferences is conscious or not), and thus violations of these preferences seem like particularly bad outcomes. For preference utilitarianists, killing an unconscious person for no good reason seems really bad. So, preference utilitarianism makes good sense out of these problematic cases and shows how the actions performed could be morally wrong.

Given this understanding of Peter Singer's ethic, we can begin to see that unplugging the violinist - and thereby killing an unconscious person - might be the wrong course of action. Of course, making a summary moral judgment on an act from a preference utilitarian perspective demands more than this, requiring that one look at all of the possible outcomes of a situation and deciding which satisfy the most preferences. Thomson's violinist thought experiment makes it 
particularly easy on us, as she entertains only two possible actions. You may either sustain the life of the violinist by remaining attached to him for nine months, or you may unplug yourself from the violinist, ending his life and liberating your own.

If you sustain the life of the violinist, it seems that you commit to some bad consequences. Thomson is clearly aware of this. The worst seems to be that you are forced to remain in a hospital bed for nine months, unable to do your normal activities. From familial to financial to societal costs, you will give up quite a bit if you choose to remain in bed for nine months, and you likely will have a strong preference to do otherwise. Furthermore, you will have to remain in bed, back-to-back with a sickly man, a state that you might regard as unpalatable or embarrassing, and which likely also violates your preferences. You might also be exposed to infection or other medical maladies as a result of your stay in the hospital connected to this man, which would be a further violation of your preferences.

Of course, remaining plugged into the violinist will result in some very good consequences. As a result of your willingness to participate, the violinist will go on to live out his life, pleasing the Society of Music Lovers, by whom he is adored. Furthermore, the violinist clearly has a very strong preference to continue living, even though he is unconscious, and the satisfaction of this preference seems like a really good thing. Remaining attached to the violinist would satisfy all of these preferences, as well as your likely preference to be a hero, as you surely would in the eyes of the society and the public, given that the violinist is so famous. So, it seems that there are a number of preferences that go unsatisfied if you save the violinist and there are a number of preferences that are satisfied by your decision to save the violinist.

If you decide to pull the plug on the violinist, thereby terminating his life, your decision will also end up in a combination of satisfied preferences and unsatisfied preferences. You will not have to face the practical loss of nine months of your life, and you will not have to face embarrassment or possible medical maladies. In fact, you will be free to do as you please, clearly satisfying your preferences. On the other hand, such an action will result in the severe dissatisfaction of the violinist, who surely wants to continue living. It will also result in the unsatisfied preferences of all of the members of the Society of Music Lovers, plus the general public, to see the violinist continue living and to hear him play.

Is it likely that your preference not to lie in bed for nine months with the man outweighs his preference to continue living and the preference of all of the others who wish to see him continue living? It seems doubtful. For the sake of argument, let us say that the Society of Music Lovers and the public were not involved, and that the only violated preference was the preference of the violinist to continue living. Even if this were the case, could one's desire to be free rather than lying in a bed with an unconscious stranger for nine months possibly outweigh the man's preference to continue living?

It seems that even if nine unencumbered months were to be fantastically wonderful, full of vacations and friendships and other pleasures, the nine months of freedom would not outweigh the continuity of the man's life, even if his life were completely average and unremarkable. Indeed, we would think it to be morally outrageous to kill a complete stranger on the street, just because it brought one nine months of extreme pleasure. In other words, it seems obvious that 
your preferences to spend the next nine months quite differently do not morally outweigh the violinist's preference to live.

With this established, it seems that we can make a plausible summary moral judgment on the case. It would be morally impermissible for you to unplug yourself from the violinist, thereby terminating his life, and it is morally obligatory that you go on sustaining his life by lying in bed beside him for the next nine months. This would not be a comfortable choice, but preference utilitarianism explains why this is quite clearly the right thing to do in such difficult circumstances.

This analysis by itself does not tell us much. It is unlikely that any reader of this paper would ever be in the situation described in Thomson's thought experiment. However, according to Thomson, the thought experiment is an accurate analogy, portraying the moral dilemma involved in the decision surrounding abortion, granting that a fetus is a full person. Although some may deny that the analogy holds, the parallel between the unconscious violinist thought experiment and early-stage pregnancy is clear. In both cases, an unconscious person is biologically attached to another person in such a way that the termination of the connection will result in the termination of the unconscious person's life. In both cases, this connection must persist for nine months for the unconscious person to become a conscious and autonomous being, capable of sustaining his or her own life without direct connection to the other individual. There are some important distinctions between the two cases, but most of these problems can be worked out by tweaking the thought experiment: see, for example, Chapter Six of Singer's Practical Ethics (2011). In many important respects, the cases are roughly analogous.

If the cases are roughly analogous, and pregnancy is indeed like Thomson says it is, then this presents a problem for Thomson. If we assume that human fetuses are persons, and if it is morally impermissible for you to unplug yourself from the violinist, then it follows that it is morally impermissible to terminate a pregnancy in abortion. Given these relevant facts, this seems intuitive, and comports well with Singer's preference utilitarianism. Thomson's task was to show that it is always morally permissible to have an abortion even if fetuses are considered persons. But the tool of preference utilitarianism shows this to be clearly false. In fact, many other versions of consequentialism are likely to reach the same conclusion when applied to this thought experiment. Feldman's Justified Act Utilitarianism (1993) is one example. On consequentialist grounds, abortion of a fetus that is a person may be justifiable in principle, but in most actual cases such an abortion is morally impermissible.

An obvious objection to all this might as follows: Singer believes that preference utilitarianism is true and that Thomson's analogy is ingenious, but Singer is a proponent of infanticide. So it surely cannot be true that preference utilitarianism shows abortion to be wrong in most cases. The objection is interesting, but it seems to overlook an important difference between the claims about personhood that Singer holds to be true and the claim about personhood that Thomson has granted as true in her thought experiment. Because Singer is an empirical functionalist, he believes that personhood and the values that can be ascribed to it vary by degrees. He believes that one who possesses a greater awareness of self is more of a person than one who possesses a lesser awareness of self, for example. Thus, Singer does not see fetuses as humans that are fully persons. As a result, he sees their preferences as less important than the preferences of those with 
greater self-awareness and ability to project themselves into the future. Surely, thinks Singer, fetuses experience less displeasure when their lives are ended compared to the displeasure experienced by a dying young adult. Although this is likely be true, given that preferences by their very nature are things available even to the unconscious and to those who cannot experience displeasure, it seems that preferences are not dependent upon the state of one's mental faculties. If a fetus is a person, then it seems right to regard the fetus's preferences in the same way one would regard an unconscious adult's preferences. Most people find their lives worth living and want to continue living, so we can be quite confident that both the unconscious adult and the fetus have preferences for the continuity of their lives unless we are given some strong reason to think otherwise.

In conclusion, we have seen that Thomson's "A Defense of Abortion," though very influential in the realm of abortion ethics, does not hold up to the moral scrutiny demanded by preference utilitarianism. Moreover, preference utilitarianism gives us good reasons to think that having an abortion for no good reason is a bad thing, and that in most cases having an abortion is morally impermissible.

This all may come as a surprise for many acquainted with the kinds of ruthless ideals and atrocious acts commonly associated with consequentialism. Utilitarianism has been used to justify some truly heinous acts, most notably the Holocaust under the influence of Nazi Germany (Bekier, 2010). Furthermore, it seems plausible to suggest that if Peter Singer himself had his way, civilization would return to the Spartan ethic of slaughtering all severely disabled infants in the days following their births.

Consequentialism, like any other ideological framework, is a tool that can be used for good or for evil. It seems to be a reliable guide on ethical issues, providing us with plausible and intuitive ethical norms. Yet it also may be used to justify evil. Since it seems to be a reliable moral framework, consequentialism is most likely to promote evil ends when it is used fallibly and with an agenda in mind. Yet it is also true that fallible humans could apply consequentialism incorrectly and perpetuate evil, and perhaps even consequentialism itself could go wrong somewhere.

Whenever we make use of an ethical system, we should always be vigilant to ensure that we do as little harm as possible while seeking to do what morality demands of us. The atrocities committed under the guise of utilitarianism in the past need not dissuade us from turning to consequentialism as a reliable guide. In fact, consequentialism is a powerful tool bent on justice, defending those members of humanity that are most vulnerable; even those humans found within the womb.

\section{References}

Bekier, M. (2010). The ethical considerations of medical experimentation on human subjects. Retrieved May 8, 2013, from http://www.qcc.cuny.edu/socialsciences/ppecorino/MEDICAL_ETHICS_TEXT/Chapter 7 Human Experimentation/Reading-Nazi-experimentation.htm 
Feldman, Fred (1993). "On the Consistency of Act- and Motive-Utilitarianism: A Reply to Robert Adams". Philosophical Studies: An International Journal for Philosophy in the Analytic Tradition 70 (2).

Kouk1, G. (2003). Unstringing the violinist [Radio broadcast]. In Kouk1, G. (Executive Producer), Stand to Reason. Signal Hill, CA. Retrieved May 8, 2013, from http://www.str.org/articles/unstringing-the-violinist

MacFarquhar, N. (1999, September 22). Protest over Princeton's new ethics professor. The New York Times. Retrieved May 8, 2013, from http://www.nytimes.com/1999/09/22/nyregion/protest-over-princeton-s-new-ethicsprofessor.html

Mautner, T. (2005). Singer, peter. In T. Mautner (Ed.), The Penguin Dictionary of Philosophy (2nd ed.). London, England: Penguin Books.

Ruderman, A. (2000, March 5). Many Princeton alumni take uncharitable view. The New York Times. Retrieved May 8, 2013, from http://www.nytimes.com/2000/03/05/nyregion/many-princeton-alumni-take-uncharitableview.html

Singer, P. (1997). “A Philosophical Self-Portrait,” Thomas Mautner: The Penguin Dictionary of Philosophy. 1997, pp. 521-522.

Singer, P. (2000). Writings on an ethical life. The Ecco Press.

Singer, P. (2011). Practical ethics. (3rd ed.). Cambridge: Cambridge University Press. doi: $10.1017 / \mathrm{CBO} 9780511975950$

Specter, M. (1999, September 6). The Dangerous Philosopher, Retrieved May 8, 2013, from http://www.michaelspecter.com/1999/09/the-dangerous-philosopher/

Thomsoin, J. J. (1971). A defense of abortion. Philosophy \& Public Affairs, 1(1), 47-66. 